\title{
Assessment of pedicle size in patients with scoliosis using EOS 2D imaging: a validity and reliability study
}

\author{
C. M. M. Peeters ${ }^{1}$ - L. van Houten ${ }^{2}$. D. H. R. Kempen ${ }^{3}$ - F. H. Wapstra ${ }^{1}$. P. C. Jutte ${ }^{1} \cdot$ I. van den Akker-Scheek ${ }^{1}$. \\ C. Faber ${ }^{1}$
}

Received: 30 December 2020 / Revised: 30 December 2020 / Accepted: 6 April 2021 / Published online: 25 April 2021

(c) The Author(s) 2021

\begin{abstract}
Purpose Free-hand pedicle screw insertion methods are widely used for screw insertion during scoliosis surgery. Preoperative knowledge about the pedicle size helps to maximize screw containment and minimize the risk of pedicle breach. Radiographs taken by a biplanar low-dose X-ray device (EOS) have no divergence in the vertical plane. The criterion validity and reliability of preoperative EOS images for pedicle size measurements in patients with idiopathic scoliosis (IS) was investigated in this study.

Methods Sixteen patients who underwent surgical treatment for IS were prospectively included. Intra- and extracortical pedicle height and width measurements on EOS images were compared with reconstructed intra-operative 3D images of the isthmus of included pedicles. Secondly, intra- and interobserver reliability of pedicle size measurements on EOS images was determined.

Results The total number of analyzed pedicles was 203. The correlation between the EOS and 3D scan measurements was very strong for the intra- and extracortical pedicle height and strong for the intra- and extracortical pedicle width. There are, however, significant, but likely clinically irrelevant differences (mean absolute differences $<0.43 \mathrm{~mm}$ ) between the two measure methods for all four measurements except for extracortical pedicle height. For pedicles classified as Nash-Moe 0, no significant differences in intra- and extracortical pedicle width were observed. Both intra- and interobserver reliability was excellent for all pedicle size measurements on EOS images.

Conclusion The results of this study indicate a good validity and reliability for pedicle size measurements on EOS radiographs. Therefore, EOS radiographs may be used for a preoperative estimation of pedicle size and subsequent screw diameter in patients with IS.
\end{abstract}

Keywords Pedicle size measurements $\cdot$ EOS $\cdot$ Intra-operative 3D images $\cdot$ Scoliosis $\cdot$ Validity and reliability

\section{Background}

\section{Faber}

c.faber@umcg.nl

1 Department of Orthopaedics, University Medical Center Groningen, University of Groningen, Hanzeplein 1, 9713 GZ Groningen, P.O. Box 30.001, 9700 RB Groningen, The Netherlands

2 Department of Radiology, University Medical Center Groningen, University of Groningen, Groningen, The Netherlands

3 Department of Orthopaedics, OLVG, Amsterdam, The Netherlands
Posterior spinal instrumentation and fusion with pedicle screws is a standard practice in the surgical treatment of severe idiopathic scoliosis (IS) [1-3]. It is regarded as a safe and effective procedure in the majority of the patients [4]. However, appropriate placement of well-sized pedicle screws can be challenging in scoliosis due to the different morphometric characteristics of the pedicle dimensions and vertebral rotation [2]. As shown in earlier CT studies, there is a wide variation in pedicle shapes and sizes in a scoliotic spine [5]. Consequently, screw misplacements and under- or oversizing are risks. This subsequently increases the risk of neurologic or vascular injury, pedicle fracture, and screw loosening $[6,7]$. 
Free-hand pedicle screw insertion methods are widely used for screw insertion. Due to the variation in pedicle dimensions, it is not possible to use standardized screw diameters for each spinal levels. Previous studies showed that full containment of the screws within the cortical pedicle walls was achieved $69-94 \%$ with free-hand placement, and pedicle breach rates are reported at $9.7 \%-17.1 \%[6,7]$. Preoperative knowledge about the pedicle size helps to maximize screw containment and minimize the risk of pedicle breach. To accurately measure the pedicle sizes, a preoperative computed tomography (CT) scan is needed [8]. However, this is not done routinely in clinical practice due to the exposure of this young population to high levels of radiation. Plane radiographs as alternative have the disadvantage that there is divergence in both the horizontal and vertical planes.

The EOS imaging system can provide biplanar low-dose radiographs of the spine, which reduces the amount of radiation substantially in comparison with CT and conventional radiographs $[9,10]$. Furthermore, images have no divergence in the vertical plane since the system uses a $\mathrm{C}$-arm. Despite these advantages, the reliability of the EOS imaging system for pedicle size measurements has not been investigated.

The purpose of this study was to assess the validity and intra- and interobserver reliability of preoperative EOS images for measurements of the pedicle heights and widths in patients with IS.

\section{Methods}

\section{Patients}

This study was approved by the Medical Ethical Review Board (RR-Number: 201800917) and carried out in the University Medical Center Groningen (UMCG). After obtaining informed consent, patients were prospectively included from October 2018 to April 2019. Inclusion criteria were: (1) IS patients aged between 12 and 25 years with (2) a Cobb angle of the thoracic and/or lumbar curve of 50 degrees or more (3) undergoing surgical correction. Patients with spinal anomalies or previous spine operations were excluded.

\section{Medical imaging}

Routine biplanar low-dose radiographs of the spine were made preoperatively with the EOS system (EOS imaging, Paris, France). Patients were positioned on the EOS platform in standing position. Surgical treatment was performed using routine intra-operative 3D imaging (Siemens Arcadis Orbic 3D C-arm) and navigation system (Stryker). These intra-operative 3D images were used as "gold standard" in this study.

\section{Method of measurements}

Two independent observers ( $\mathrm{CP}$ and $\mathrm{LH})$, residents from the department of orthopedic surgery and radiology, analyzed the pedicle sizes in the preoperative EOS images and intra-operative 3D images. Both observers were blinded for the scoring of the other observer. One observer (CP) performed all measurements twice with a week between the measurements. The pedicle sizes were measured with Advanced PACS Viewer. The standing AP view was used for measurements on the EOS images. For the intra-operative $3 \mathrm{D}$ scan, the vertical plane perpendicular on the lines of the transverse and sagittal pedicle angle was reconstructed at the narrowest part (isthmus) of each individual pedicle (Fig. 1). The analysis of each pedicle consisted of the largest intracortical and extracortical diameter of the height and width of the pedicle isthmus (Figs. 1, 2). The Nash and Moe method was used on the EOS AP view to determine the vertebral rotation [11]. Pedicles on the concave side with a Nash-Moe rotation score $\geq 2$ were not measurable and therefore excluded from analysis.

\section{Statistical analyses}

Paired-sample T-tests were used to compare differences in the mean pedicle size measurements between EOS images and intra-operative 3D images measurements. Spearman's rho correlation coefficients were calculated between intraand extracortical pedicle height and width measurements on EOS and intra-operative 3D images. A Spearman's rho of $0.90-1.00$ indicates a very strong correlation, a rho of $0.70-0.89$ indicates a strong correlation, $0.50-0.69$ moderate, $0.26-0.49$ weak, and $<0.25$ indicates little if any correlation $[12,13]$. Absolute agreement was evaluated with Bland-Altman plots [14]. If the $95 \%$ confidence interval (CI) of the mean difference between the two measurements contains zero, then no systematic bias is present between the measurements on EOS and intra-operative 3D images [15].

ANOVA with post hoc Tukey tests was used to assess the influence of Nash-Moe vertebral rotation score and spinal level on the mean differences between EOS and 3D pedicle size measurements. For this, the data were clustered in three Nash-Moe groups $(0,1$, and $2-3)$ and four spinal level groups (T3-T5, T6-T9, T10-L1, and L2-L5). Since there were only few pedicles with a Nash-Moe score 3 , they were clustered with Nash-Moe score 2 as one group.

The relative and absolute intra- and interobserver reliability was determined. The relative intra- and interobserver reliability was assessed by calculating the intraclass 

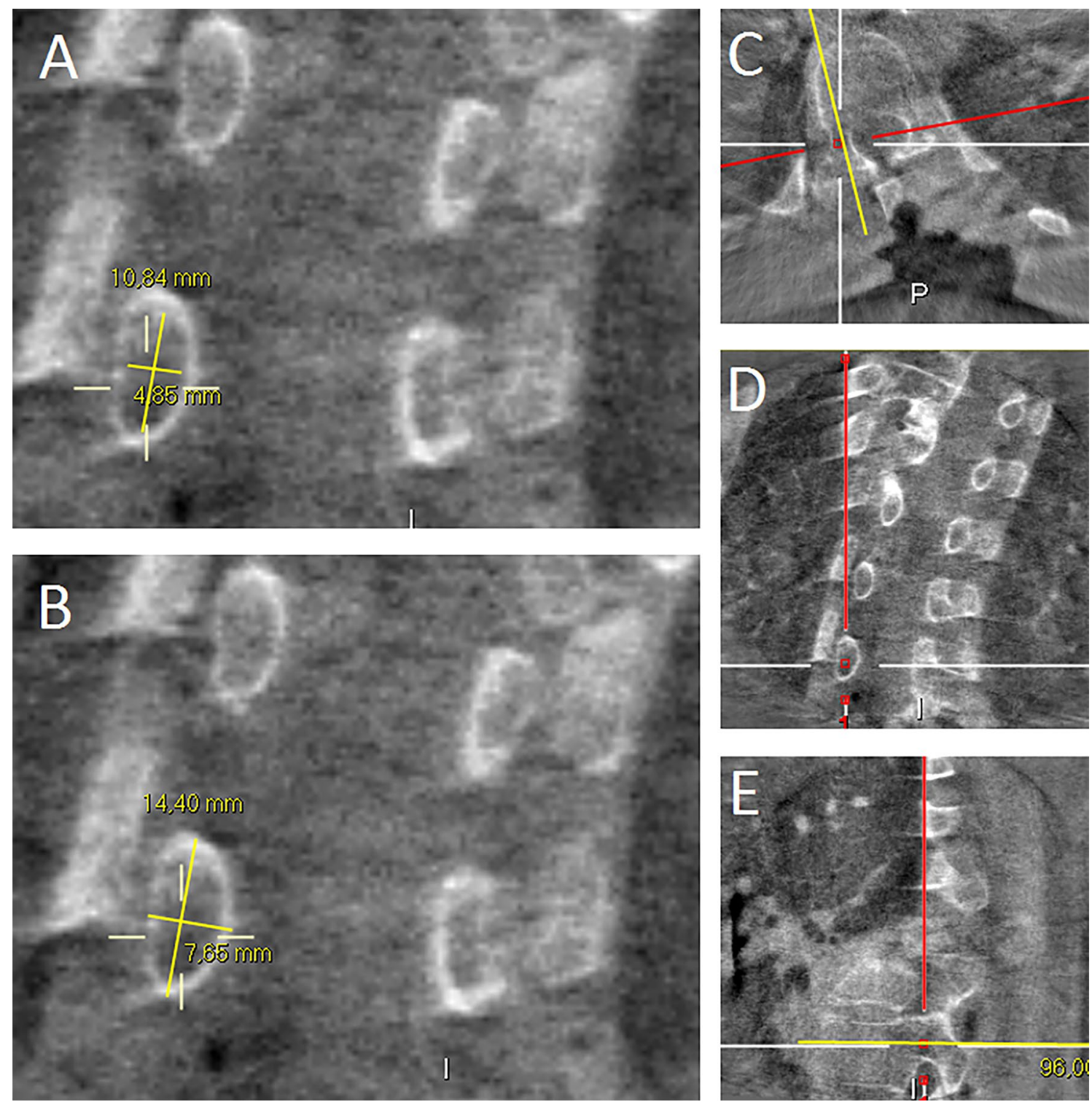

Fig. 1 Intracortical (a) and extracortical (b) pedicle height and width measurements on intra-operative 3D images. The vertical plane (d) on the lines of the transverse (c) and sagittal pedicle angle (d) was reconstructed at the narrowest part (isthmus) of each individual pedicle

correlation coefficients (ICCs) (two-way random, absolute agreement) for each intra- and extracortical pedicle height and width measurements on the EOS radiographs [15]. ICC greater than 0.9 indicates excellent reliability, values of $0.75-0.9$ indicate good reliability, values of $0.5-0.7$ indicate moderate reliability, and ICCs less than 0.5 are considered to indicate poor reliability [16]. The Bland-Altman method was used to evaluate the absolute intra- and interobserver reliability [14]. IBM SPSS Statistics for Windows, version 23.0 (IBM Corp., Armonk, NY, USA), was used for statistical analysis. A $P$-value $<0.05$ was considered to be statistically significant.

\section{Results}

\section{Patient inclusion and characteristics}

Sixteen patients with a mean preoperative Cobb angle of 60 degrees $(\mathrm{SD}=6.8)$ and a mean age of 16 years $(\mathrm{SD}=2.6)$ were included in the study (Table 1). Fourteen patients $(87.5 \%)$ were female. The total number of pedicles measurements for comparing EOS and 3D imaging was 203. Most patients $(81 \%)$ had a right thoracic structural 

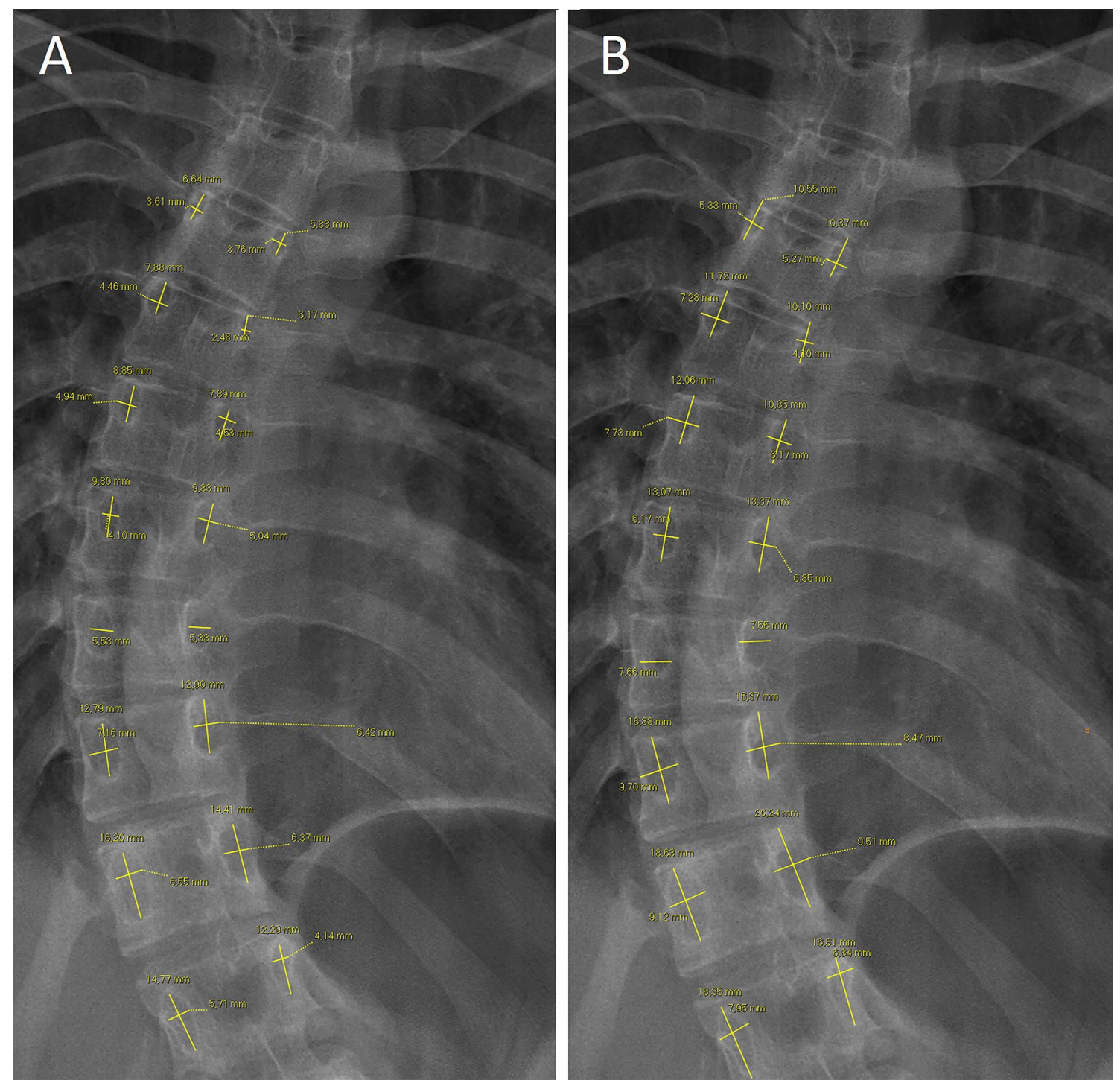

Fig. 2 Intracortical (a) and extracortical (b) pedicle height and width measurements on preoperative EOS images

scoliosis. Sixty-one pedicles on the concave side with a Nash-Moe grade score $\geq 2$ could not be measured.

\section{Validity of EOS measurements}

The correlation between the EOS and intra-operative 3D measurements was very strong for the intracortical pedicle height (Spearman's rho $=0.93$ ) and strong for the intracortical (Spearman's rho $=0.85$ ) and extracortical (Spearman's rho $=0.87$ ) pedicle width (Table 2). Significant differences in intracortical pedicle height, intracortical pedicle width, and extracortical pedicle width between EOS and intra-operative 3D measurements were established. The Bland-Altman plots showed a systematic bias in all three measurements. The intracortical pedicle height was systematically measured larger on EOS images (mean height: 9.01 vs. $8.64 \mathrm{~mm}$ for
EOS and 3D run, respectively). The intra- and extracortical pedicle width was systematically measured smaller on the EOS images than on the intra-operative 3D images (Table 2).

There were no significant differences in extracortical pedicle height between the two measurement methods (Table 2). The Bland-Altman plot showed also no significant bias, and the correlation between the two measure methods was very strong (Spearman's rho $=0.95$ ). The mean difference of the pedicle size measurements between EOS and 3D varied between 0.06 and $0.43 \mathrm{~mm}$.

\section{Influence of Nash-Moe scores on mean differences between EOS and 3D}

The comparisons of EOS and intra-operative 3D measurements of pedicles with a Nash-Moe score 0,1 , and 2-3 
Table 1 Characteristics of the included patients

\begin{tabular}{|c|c|c|c|c|c|c|}
\hline Patient & Gender & Age (y) & CA (degrees) & Fusion levels & $N$ pedicles & $\begin{array}{l}N \text { pedicles Nash- } \\
\text { Moe score: } 0(1) \\
{[2]\{3\}}\end{array}$ \\
\hline 1 & $\mathrm{~F}$ & 14 & 70 & T4-L1 & 13 & $6(3)[3]\{1\}$ \\
\hline 2 & $\mathrm{~F}$ & 19 & 52 & T4-L1 & 12 & $2(5)[5]\{0\}$ \\
\hline 3 & $\mathrm{~F}$ & 13 & 58 & T3-L1 & 15 & $0(13)[2]\{0\}$ \\
\hline 4 & $\mathrm{~F}$ & 20 & 52 & $\mathrm{~T} 4-\mathrm{T} 12$ & 16 & $4(12)[0]\{0\}$ \\
\hline 5 & $\mathrm{~F}$ & 15 & 60 & $\mathrm{~T} 4-\mathrm{T} 12$ & 13 & $2(7)[4]\{0\}$ \\
\hline 6 & $\mathrm{~F}$ & 14 & 71 & T4-L4 & 16 & $2(7)[4]\{3\}$ \\
\hline 7 & $\mathrm{~F}$ & 14 & 70 & T3-L2 & 11 & $0(8)[2]\{1\}$ \\
\hline 8 & $\mathrm{~F}$ & 18 & 53 & T4-L1 & 11 & $3(4)[4]\{0\}$ \\
\hline 9 & $\mathrm{~F}$ & 17 & 64 & T3-T12 & 11 & $2(3)[6]\{0\}$ \\
\hline 10 & $\mathrm{~F}$ & 16 & 56 & T3-T11 & 14 & $6(6)[2]\{0\}$ \\
\hline 11 & $\mathrm{~F}$ & 15 & 60 & T4-L5 & 17 & $4(8)[5]\{0\}$ \\
\hline 12 & M & 16 & 62 & T4-L1 & 14 & $6(4)[4]\{0\}$ \\
\hline 13 & $\mathrm{~F}$ & 22 & 65 & T3-T11 & 11 & $2(6)[3]\{0\}$ \\
\hline 14 & $\mathrm{~F}$ & 13 & 62 & T4-L1 & 11 & $3(3)[5]\{0\}$ \\
\hline 15 & $\mathrm{~F}$ & 15 & 54 & $\mathrm{~T} 4-\mathrm{T} 11$ & 10 & $2(5)[3]\{0\}$ \\
\hline 16 & M & 18 & 50 & T9-L4 & 8 & $2(2)[4]\{0\}$ \\
\hline Total & & & & & 203 & $46(96)[56]\{5\}$ \\
\hline
\end{tabular}

$F$ female, $M$ male, $y$ years $C A$ preoperative Cobb angle, $T$ thoracic vertebra, $L$ lumbar vertebra, $N$ pedicles, number of measured pedicles for the comparison between EOS and 3D imaging

Table 2 Comparison of EOS and intra-operative 3D measurements

\begin{tabular}{|c|c|c|c|c|c|c|c|c|}
\hline Measurement & $N$ & Mean EOS (mm) & Mean 3D (mm) & $\begin{array}{l}\text { Mean difference }{ }^{\mathrm{a}}(95 \% \\
\mathrm{CI})\end{array}$ & $\mathrm{SD} \Delta$ & $\begin{array}{l}\text { Range of } \\
\text { difference } \\
\text { EOS-3D }\end{array}$ & $P$-value & Spearman's rho \\
\hline $\begin{array}{l}\text { Intracortical pedicle } \\
\text { height }\end{array}$ & 192 & 9.01 & 8.64 & $0.36(0.22-0.50)$ & 0.98 & $-2.28-3.91$ & $<0.01 *$ & 0.927 \\
\hline $\begin{array}{l}\text { Extracortical pedicle } \\
\text { height }\end{array}$ & 193 & 13.42 & 13.36 & $0,06(-0.07-0.19)$ & 0.90 & $-2.62-3.66$ & 0.36 & 0.948 \\
\hline $\begin{array}{l}\text { Intracortical pedicle } \\
\text { width }\end{array}$ & 199 & 3.63 & 3.87 & $-0.23(-0.34--0.12)$ & 0.80 & $-3.03-1.58$ & $<0.01 *$ & 0.852 \\
\hline $\begin{array}{l}\text { Extracortical pedicle } \\
\text { width }\end{array}$ & 201 & 6.00 & 6.43 & $-0.43(-0.57--0.30)$ & 0.97 & $-3.68-2.09$ & $<0.01 *$ & 0.870 \\
\hline
\end{tabular}

$N$ number of compared pedicles, $m m$ millimeters, $S D$ standard deviation, $C I$ confidence interval, $S D \Delta$ standard deviation of mean difference, EOS, EOS images; $3 D$, intra-operative $3 D$ images; $P$ P-value

${ }^{a}$ Mean difference was calculated by subtracting the intra-operative $3 D$ measurements from the EOS measurements

${ }^{*}$ indicates a statistically significant difference $(P<0.05)$

are presented in supplementary data 1 in the same way as Table 2. The mean difference of EOS and 3D intracortical pedicle width measurements was significantly larger for pedicles with Nash-Moe score 2-3 (mean difference: $-0.47 \mathrm{~mm}$ ), compared to pedicles with Nash-Moe score 0 (mean difference: $-0.06, P=0.03$ ) or Nash-Moe score 1 (mean difference: $-0.16, P=0.04$ ). No other significant differences between the Nash-Moe groups were observed.

\section{Influence of spinal level on mean differences between EOS and 3D}

The mean absolute difference between EOS and 3D intracortical pedicle width measurements was significant smaller for the group pedicles from spinal levels T3-T5, compared to pedicles from spinal levels T10-L1 (mean difference: 0.13 vs. $-0.35 \mathrm{~mm}$ for T3-T5 and T10-L1, 
respectively, $P=0.04$ ). Also for extracortical pedicle width significant smaller mean absolute differences were established for pedicles from spinal levels T3-T5 (mean difference $=0.02 \mathrm{~mm}$ ) and T6-T9 (mean difference: $-0.29)$, compared to pedicles from spinal levels T10-L1 (mean difference: $-0.74 \mathrm{~mm}, P=<0.01$ and $P=0.01$, respectively). No other significant differences were found between the different spinal level groups. Box plots of the EOS and intra-operative 3D pedicle size measurements for each spinal level are presented in supplementary data 2-5.

\section{Intraobserver and interobserver reliability}

Relative intra- and interobserver reliability was excellent for all pedicle size measurements on EOS (all ICC's $\geq 0.94$, see Tables 3,4). The mean difference of the measurements varied between 0.02 and $0.37 \mathrm{~mm}$. In the absolute intraobserver reliability analysis, there was no systematic bias between the two EOS intracortical pedicle height and width measurements. A systematic bias was observed in EOS extracortical pedicle height $(95 \% \mathrm{CI}=0.03-0.23 \mathrm{~mm})$ and width measurements (95\% CI $=0.01-0.17 \mathrm{~mm}$, see Table 3). Regarding interobserver reliability, there was no systematic bias between EOS intracortical pedicle width measurements.

Table 3 Intraobserver reliability of EOS measurements

\begin{tabular}{|c|c|c|c|c|c|c|c|c|c|}
\hline Measurement & Mean M1 (SD) & Mean M2 (SD) & $\begin{array}{l}\text { Mean difference } \\
(95 \% \text { CI })\end{array}$ & $\mathrm{SD} \Delta$ & SEM & SDC & $\begin{array}{l}\text { Range of } \\
\text { difference } \\
\text { M1-M2 }\end{array}$ & $P$-value & ICC (95\% CI) \\
\hline $\begin{array}{l}\text { Intracortical pedicle } \\
\text { height }\end{array}$ & $9.00(2.48)$ & $9.03(2.55)$ & $-0.03(-0.13-0.06)$ & 0.69 & 0.49 & 1.36 & $-2.15-2.74$ & 0.49 & $0.96(0.95-0.97)$ \\
\hline $\begin{array}{l}\text { Extracortical pedicle } \\
\text { height }\end{array}$ & $13.42(2.82)$ & $13.29(2.86)$ & $0.13(0.03-0.23)$ & 0.69 & 0.49 & 1.36 & $-1.91-2.44$ & $0.01 *$ & $0.97(0.96-0.98)$ \\
\hline $\begin{array}{l}\text { Intracortical pedicle } \\
\text { width }\end{array}$ & $3.63(1.36)$ & $3.65(1.42)$ & $-0.02(-0.08-0.04)$ & 0.41 & 0.29 & 0.80 & $-2.87-1.27$ & 0.48 & $0.96(0.94-0.97)$ \\
\hline $\begin{array}{l}\text { Extracortical pedicle } \\
\text { width }\end{array}$ & $6.00(1.66)$ & $5.91(1.66)$ & $0.09(0.01-0.17)$ & 0.57 & 0.40 & 1.11 & $-2.45-3.12$ & $0.02 *$ & $0.94(0.92-0.95)$ \\
\hline
\end{tabular}

Pedicle height and width measurements are expressed in millimeters $(\mathrm{mm})$

$M 1$ measurement 1 from observer one (CP), M2 measurement 2 from observer one (CP), $m m$ millimeters, $S D$ standard deviation, $C I$ confidence interval, $S D \Delta$ standard deviation of mean difference, $S E M$ standard error of measurement, $S M C$ smallest detectable change, $P P$-value, $I C C$ intraclass correlation coefficient

${ }^{a}$ Mean difference was calculated by subtracting $M 2$ from $M 1$

${ }^{*}$ indicates a statistically significant difference $(P<0.05)$

Table 4 Interobserver reliability of EOS measurements

\begin{tabular}{|c|c|c|c|c|c|c|c|c|}
\hline Measurement & Mean Ob 1 (SD) & Mean Ob 2 (SD) & $\begin{array}{l}\text { Mean difference }{ }^{a} \\
(95 \% \text { CI })\end{array}$ & $\mathrm{SD} \Delta$ & SEM & SDC & $\begin{array}{l}\text { Range of } \\
\text { difference } \mathrm{Ob} \\
1-\mathrm{Ob} 2\end{array}$ & $P$-value $\operatorname{ICC}(95 \% \mathrm{CI})$ \\
\hline $\begin{array}{l}\text { Intracortical pedi- } \\
\text { cle height }\end{array}$ & $9.01(2.48)$ & $8.64(2.53)$ & $0.37(0.27-0.47)$ & 0.72 & 0.51 & 1.41 & $-1.31-2.49$ & $<0.01 * 0.95(0.90-0.97)$ \\
\hline $\begin{array}{l}\text { Extracortical pedi- } \\
\text { cle height }\end{array}$ & $13.42(2.82)$ & $13.26(3.00)$ & $0.16(0.05-0.27)$ & 0.78 & 0.55 & 1.52 & $-3.12-2.75$ & $0.01 * 0.96(0.95-0.97)$ \\
\hline $\begin{array}{l}\text { Intracortical pedi- } \\
\text { cle width }\end{array}$ & $3.63(1.36)$ & $3.57(1.39)$ & $\begin{array}{l}0.06(<-0.01- \\
0.13)\end{array}$ & 0.47 & 0.33 & .91 & $-2.83-1.71$ & $0.06 \quad 0.94(0.92-0.96)$ \\
\hline $\begin{array}{l}\text { Extracortical pedi- } \\
\text { cle width }\end{array}$ & $6.00(1.66)$ & $5.77(1.65)$ & $0.23(0.15-0.31)$ & 0.55 & 0.39 & 1.08 & $-1.14-2.41$ & $<0.01 * 0.94(0.90-0.96)$ \\
\hline
\end{tabular}

Pedicle height and width measurements are expressed in millimeters $(\mathrm{mm})$

$O b 1$ measurement 1 from observer one (CP), Ob 2 measurement from observer two (LH), mm millimeters, $S D$ standard deviation, $C I$ confidence interval, $S D \Delta$ standard deviation of mean difference, $S E M$ standard error of measurement, $S M C$ smallest detectable change, $P P$-value, ICC intraclass correlation coefficient

${ }^{a}$ Mean difference was calculated by subtracting M2 from M1

${ }^{*}$ indicates a statistically significant difference $(P<0.05)$ 
For the EOS intracortical $(95 \% \mathrm{CI}=0.27-0.47 \mathrm{~mm})$ and extracortical pedicle height $(95 \% \mathrm{CI}=0.05-0.27 \mathrm{~mm})$ and extracortical pedicle width $(95 \% \mathrm{CI}=0.15-0.31 \mathrm{~mm})$, a systematic bias was observed (Table 4).

\section{Discussion}

The results of this study show a very strong correlation between the EOS and intra-operative 3D measurements for the intra- and extracortical pedicle height and a strong correlation for the intra- and extracortical pedicle width, indicating a good validity of EOS measurements. The mean absolute differences of the measurements between the two methods were small $(0.06 \mathrm{~mm}-0.43 \mathrm{~mm})$, but a systematic bias existed in all measurements, except for the extracortical pedicle height. The correlation was weaker but still strong for pedicles with a Nash-Moe score 2-3, compared to pedicles of vertebral bodies with less rotation. The mean absolute differences were often smaller for pedicles from higher spinal levels, which could be explained by the generally smaller pedicle sizes. Both intra- and interobserver reliability was excellent for all pedicle size measurements on EOS images.

A stronger correlation between EOS and intra-operative 3D measurements was observed for pedicle height measurements (very strong correlation) compared to pedicle width measurements (strong correlation). In particularly, pedicles with a Nash-Moe score 2 or 3 showed weaker correlation for the intra- and extracortical pedicle width measurements. This was expected for two reasons. First, the EOS imaging system uses a $\mathrm{C}$-arm with the result that there should be no divergence in the vertical plane, but there still is in the horizontal plane. Vertebral bodies with pedicles with Nash-Moe score 2 and 3 are generally positioned closer to the apex of the scoliosis curve and therefore wider from the $\mathrm{C} 7$ plumb line than vertebral bodies with less rotation. Consequently, these pedicles near the apex have theoretically a more adverse effect of the divergence in the horizontal plane. Since there was a systematically measured smaller intra- and extracortical pedicle width of Nash-Moe 2 and 3 pedicles (mean difference was $-0.47 \mathrm{~mm}$ and $-0.51 \mathrm{~mm}$ for intra- and extracortical pedicle width measurements, respectively) and no significant difference for pedicles classified as Nash-Moe 0 on the EOS images compared to intra-operative 3D images, the adverse effect of the divergence by the EOS imaging system was not regarded as a relevant factor and vertebral rotation is a more logic explanation for this systematic underestimation.

The transverse and sagittal pedicle axis lines have been described as the ideal pedicle screw trajectory in which each pedicle appeared largest, and are used for pedicle screw placements with intra-operative 3D imaging and navigation systems $[5,17,18]$. Therefore, the vertical plane perpendicular on these two lines was reconstructed at the isthmus of each pedicle for the pedicle size measurements on the intra-operative 3D scans. The isthmus is the smallest part of the pedicle through which a pedicle screw is mostly placed, so the strong correlation between the pedicle size measurements on this vertical plane and size measurements on EOS images found in this study is of great interest for providing a preoperative indication of needed pedicle screw diameters. Although a commonly accepted criterion for pedicle screw diameter selection has not yet been proposed in the literature, the systematic review of studies with recommendations by Solitro et al. (2019) reported a screw diameter ranging from $80 \%$ to a maximum value of $125 \%$ of the pedicle width $[7,19,20]$. The human cadaver study of Christodoulou et al. (2005) described that the outer screw diameter should match precisely the intracortical pedicle width without ever exceeding the extracortical pedicle width [21]. However, in pediatric populations, the recommendations for maximum screw diameter/pedicle width ratio ranged from 1.15 to 1.25 [7]. These higher values were explained by the relative plasticity of the pedicle cortex in the pediatric spine [20,22].

\section{Clinical implications}

In daily practice, surgeons using free-hand pedicle screw insertion methods can preoperatively reliably measure intraand extracortical pedicle widths on EOS radiographs for an indication of the needed pedicle screw diameters for those individual pedicles. They should, however, be aware of the small systematic underestimation of the pedicle width measurements on EOS images when measuring visible pedicles from rotated vertebrae. On the other hand, since pedicle screws generally differ $1 \mathrm{~mm}$ in diameter sizes, these small underestimations are likely clinically irrelevant. Surgeons performing scoliosis surgeries with intra-operative 3D imaging and a pedicle screw navigation system could also benefit from preoperative knowledge of pedicle sizes, as for determining the optimal screw trajectory less resolution and therefore less radiation is needed, further reducing the intraoperative dose.

\section{Limitations}

Intra-operative 3D images were used as a standard technique for pedicle size measurements in this study. Although a preoperative $\mathrm{CT}$ is regarded as the gold standard, the intraoperative 3D rotational X-ray technique has also shown an accurate correspondence with anatomic sections [23]. In addition, the intra- and interobserver reliability was excellent for all pedicle size measurements on intra-operative 3D images (ICCs $>0.95$, see supplementary data 6,7 ). 
A limitation of measuring pedicle sizes on EOS radiographs is that not every pedicle of the scoliotic spine can be measured due to overprojection or vertebral rotation. Pedicles on the concave side with a Nash-Moe grade score $\geq 2$, for example, cannot be measured. Unfortunately, the pedicle size of convex pedicle at this vertebra is not representative for the contralateral concave pedicle due to the asymmetry in IS [5,24]. This pedicle asymmetry has also been found in this study when left- and right-sided pedicle sizes were compared on the intra-operative 3D scans (results not shown).

In conclusion, the results of this study indicate a good validity and reliability for pedicle size measurements on EOS radiographs. For pedicles classified as Nash-Moe 0, no significant differences in intra- and extracortical pedicle width were observed, but when measuring pedicles with a Nash-Moe score $>0$ surgeons should be aware of a significant systematic small underestimation of the pedicle width measurements on EOS images. As a result, EOS radiographs may be used for a preoperative estimation of pedicle size and subsequent screw diameter in patients with IS.

Supplementary Information The online version contains supplementary material available at https://doi.org/10.1007/s00586-021-06839-8.

Acknowledgements All authors have made direct contributions to the intellectual content of the paper and have approved the final version of the paper. The material in this paper has not been previously published or submitted elsewhere for publication. Each author believes that the manuscript represents honest work. All authors have nothing to disclose. This study was approved by the Medical Ethical Review Board (RR-Number: 201800917). The manuscript submitted does not contain information about medical device(s)/drug(s).

Funding The authors did not receive support from any organization for the submitted work. No funding was received to assist with the preparation of this manuscript. No funding was received for conducting this study. No funds, Grants, or other support was received.

\section{Declarations}

Conflict of interest The authors have no relevant financial or non-financial interests to disclose. The authors have no conflicts of interest to declare that are relevant to the content of this article. All authors certify that they have no affiliations with or involvement in any organization or entity with any financial interest or non-financial interest in the subject matter or materials discussed in this manuscript. The authors have no financial or proprietary interests in any material discussed in this article.

Open Access This article is licensed under a Creative Commons Attribution 4.0 International License, which permits use, sharing, adaptation, distribution and reproduction in any medium or format, as long as you give appropriate credit to the original author(s) and the source, provide a link to the Creative Commons licence, and indicate if changes were made. The images or other third party material in this article are included in the article's Creative Commons licence, unless indicated otherwise in a credit line to the material. If material is not included in the article's Creative Commons licence and your intended use is not permitted by statutory regulation or exceeds the permitted use, you will need to obtain permission directly from the copyright holder. To view a copy of this licence, visit http://creativecommons.org/licenses/by/4.0/.

\section{References}

1. McCormick J, Aebi M, Toby D et al (2013) Pedicle screw instrumentation and spinal deformities: have we gone too far? Eur Spine J 22(Suppl 2):S216-S224

2. Kotani T, Akazawa T, Sakuma T et al (2014) Accuracy of pedicle screw placement in scoliosis surgery: a comparison between conventional computed tomography-based and O-arm-based navigation techniques. Asian Spine J 8:331-338

3. Maruyama T, Takeshita K (2008) Surgical treatment of scoliosis: a review of techniques currently applied. Scoliosis 3:6

4. Stepanovich MMG, Yaszay B (2015) Complications of the treatment of adolescent idiopathic scoliosis. Semin Spine Surg 27:58-61

5. Brink RC, Schlosser TPC, Colo D et al (2017) Asymmetry of the vertebral body and pedicles in the true transverse plane in adolescent idiopathic scoliosis: a CT-based study. Spine Deform $5: 37-45$

6. Chan A, Parent E, Narvacan K et al (2017) Intraoperative image guidance compared with free-hand methods in adolescent idiopathic scoliosis posterior spinal surgery: a systematic review on screw-related complications and breach rates. Spine J $17: 1215-1229$

7. Solitro GF, Whitlock K, Amirouche F et al (2019) Currently adopted criteria for pedicle screw diameter selection. Int J Spine Surg 13:132-145

8. Belmont PJ Jr, Klemme WR, Dhawan A et al (2001) In vivo accuracy of thoracic pedicle screws. Spine 26:2340-2346

9. Somoskeoy S, Tunyogi-Csapo M, Bogyo C et al (2012) Accuracy and reliability of coronal and sagittal spinal curvature data based on patient-specific three-dimensional models created by the EOS 2D/3D imaging system. Spine J 12:1052-1059

10. Vidal C, Ilharreborde B, Azoulay R et al (2013) Reliability of cervical lordosis and global sagittal spinal balance measurements in adolescent idiopathic scoliosis. Eur Spine J 22:1362-1367

11. Lam GC, Hill DL, Le LH et al (2008) Vertebral rotation measurement: a summary and comparison of common radiographic and CT methods. Scoliosis 3:16

12. Meijer MF, Boerboom AL, Bulstra SK et al (2017) Do CAS measurements correlate with EOS 3D alignment measurements in primary TKA? Knee Surg Sports Traumatol Arthrosc 25:2894-2903

13. Domholdt E (2000) Physical therapy research: principles and applications. 2nd edn. WB Saunders Co., Philadelophia

14. Bland JM, Altman DG (1986) Statistical methods for assessing agreement between two methods of clinical measurement. Lancet 1:307-310

15. Rankin G, Stokes M (1998) Reliability of assessment tools in rehabilitation: an illustration of appropriate statistical analyses. Clin Rehabil 12:187-199

16. Koo TK, Li MY (2016) A guideline of selecting and reporting intraclass correlation coefficients for reliability research. J Chiropr Med 15:155-163

17. Lee DH, Lee SW, Kang SJ et al (2011) Optimal entry points and trajectories for cervical pedicle screw placement into subaxial cervical vertebrae. Eur Spine J 20:905-911

18. Lien SB, Liou NH, Wu SS (2007) Analysis of anatomic morphometry of the pedicles and the safe zone for through-pedicle procedures in the thoracic and lumbar spine. Eur Spine J 16:1215-1222 
19. Di Silvestre M, Parisini P, Lolli F et al (2007) Complications of thoracic pedicle screws in scoliosis treatment. Spine (Phila $\mathrm{Pa}$ 1976) 32:1655-61

20. Takeshita K, Maruyama T, Chikuda H et al (2009) Diameter, length, and direction of pedicle screws for scoliotic spine: analysis by multiplanar reconstruction of computed tomography. Spine (Phila Pa 1976) 34:798-803

21. Christodoulou AG, Apostolou T, Ploumis A et al (2005) Pedicle dimensions of the thoracic and lumbar vertebrae in the Greek population. Clin Anat 18:404-408

22. Suk SI, Kim WJ, Lee SM et al (2001) Thoracic pedicle screw fixation in spinal deformities: are they really safe? Spine (Phila Pa 1976) 26:2049-57
23. Verlaan JJ, van de Kraats EB, van Walsum T et al (2005) Threedimensional rotational $\mathrm{X}$-ray imaging for spine surgery: a quantitative validation study comparing reconstructed images with corresponding anatomical sections. Spine (Phila Pa 1976) 30:556-61

24. Kuraishi S, Takahashi J, Hirabayashi H et al (2013) Pedicle morphology using computed tomography-based navigation system in adolescent idiopathic scoliosis. J Spinal Disord Tech 26:22-28

Publisher's Note Springer Nature remains neutral with regard to jurisdictional claims in published maps and institutional affiliations. 